\title{
COVID-19 Pandemic Challenges and Impacts on the SDGs 2030: Indian Perspective
}

\author{
Saied Pirasteh, Hishmi Jamil Husain and Tammineni Rajitha
}

This chapter discusses the understanding of COVID-19 issues and its influences on Sustainable Development Goals (SDGs) 2030, particularly the Indian perspective. We require adopting interdisciplinary efforts and determining the challenges of social and education, economy, and health. COVID-19 global disaster has given us a big lesson on how transparent and reliable data with spatial information is efficient during an unexpected issue. Nevertheless, today, the world needs to work together on various aspects of disaster risk reduction, mitigation, and prevention. For example, it is strengthening regional cooperation in geospatial data sharing for mitigation of COVID-19 pandemics.

\subsection{Introduction}

The 2030 Agenda of Sustainable Development was launched in 2015 to foster a new 'Global Partnership' for sustainable development of the world. There are 17 SDGs with 169 targets and 232 indicators that demand the transformation of current systems for an equitable society and a healthy planet [1]. The achievement of SDGs requires strong political will and ambitious action by all stakeholders. The year 2020 remarkably shows the beginning of a decade of action to deliver the SDGs by 2030 [2]. It is a significant period for fulfilling the agenda, but in a very short period of time, with the unfortunate spread of the novel coronavirus, a global public health emergency happened, and the years of progress has been reversed. This global health crisis has changed the world as we know it. It has attacked societies at their core. It has affected not only human health but also the economy and social structures. The International Monetary Fund (IMF) has reassessed the prospect for growth for 2020 and 2021 and declared a recession period. It projects recovery in 2021 only if the world succeeds in containing the virus and take the necessary economic measures. In such an unprecedented situation, there is a tangible impact on all 17 goals. A global level impact has been summarized by the United Nations Department of Economic and Social Affairs (UNDESA) in the following infographic [3].

The authors believe that the work towards achieving SDGs begins with taking the SDGs from global to local. The first step is setting the national and subnational context of the 2030 agenda. Once the context is set, the goals and targets have to be adapted from national to local levels, and indicators have to identify, local means and structures of implementation have to design, and monitoring frameworks have to be created from national to local levels [4].

This chapter is an effort to document the impact of COVID-19 on the progress and status of the 17 sustainable development goals in India. The impact on each goal is evaluated in-depth based 
on the targets and indicators defined by India, using various reports by international agencies, newspaper reports and research publications.

\subsection{COVID-19 Impact on SDGs}

\subsubsection{SDG-1}

The goal-1 is No poverty and end poverty in all its forms everywhere. For India, there are a total of five national-level indicators that capture three out of the seven SDG targets for 2030 outlined under this goal [5]. In this study, we determined the local and global impact as follows:

The local impact of COVID-19 has been more disruptive to the urban workers who have lost their income sources than to the subsistence farmers. The subsistence farmers constitute the major percentage of the extreme poor in India, while urban workers majorly constitute the part of the population that has recently escaped from the 'extreme poverty'. The pandemic has pulled them back down, thus increasing the percentage of people living under extreme poverty in India. In addition to the above, IMF's World Economic Outlook Report 2020 has projected that India is likely to add 10 million to the poverty rolls this year and worldwide, more than 71 million [6].

The Mahatma Gandhi National Rural Employment Guarantee Act (MGNREGA) is a social refuge measure in India that aims to promise the 'right to work'. Under the MGNREGA system, the work dropped to 3.08 crore person-days in April in the aftermath of lockdown, which is $88.8 \%$ lower than April in the previous year [7]. Thus, leaving many people dependent on MGNREGA wages in rural areas with no income source. Therefore, the livelihoods of daily wage workers, migrant workers, agricultural labourers, fish workers, and others employed in the 'informal' sectors have been most severely affected. Overall, 4 million urban homeless people and 75 million inhabitants of informal settlements with no access to essential services such as water supply have suffered due to a lack of basic social protection measures [8].

In the global context, we determined that the first increase in global poverty as more than 71 million people worldwide are expected to exert back into extreme poverty [8]. Therefore, we will probably see the direct economic losses of $\$ 23.6$ billion for the countries due to natural disasters.

Decreased labour income and poor job quality have disproportionately impacted the women and young workers more, creating disparities and has been exacerbated by the COVID-19 [9]. Therefore, the economies of the least developed countries are adversely affected. We can expect that 4 billion people not covered under any sort of social protection scheme have become exposed and are more vulnerable to the impact of COVID-19.

\subsubsection{SDG-2}

The goal-2 is Zero Hunger, which enhances end hunger, achieves food security and improved nutrition, and promote sustainable agriculture. For India, there are seven national-level indicators that capture three SDG targets for 2030 outlined under this goal. In this study, we determined the local and global impact as follows:

Almost in some countries, food security becomes one of the worst affected during these times of COVID-19 pandemic. The continued lockdowns across the country have affected labour and input availability for agricultural operations. This, coupled with the serious disruption in transport networks, has impacted food security [10, 11]. For example, in India, Punjab, Haryana, and Uttar Pradesh, the largest producer of wheat, faced a crisis at the time of harvest due to shortage of labour, transportation bottlenecks and unavailability of harvesting machines [12].

Besides, due to rumours regarding the association between poultry and COVID-19, it led to a loss of Rs. 22,500 CR to the poultry industry as many farmers destroyed their produce, and some sold at very low prices [13]. The demand for processed foods saw a huge surge, but due to a shortage of raw materials, manpower and exemption permissions, the production rate was low.

As reported in the Global Nutrition Report 2020, 37.9\% of children under five years are stunted, 
and $20.8 \%$ are wasted in India, which is bound to increase with higher incidences of malnutrition [14]. Agriculture gross value added (GVA) is projected to grow by $2.5 \%$ in FY21 as compared to the average of $3.2 \%$ till 2017 due to the effect after the pandemic [15]. Bumper production of grain and horticulture output is estimated at 152.7 million tonnes and 313.35 million tonnes, respectively, even after the pandemic [16].

Considering the global impact, we estimated that 2 billion people worldwide are facing moderate food insecurity, and 700 million are facing severe food insecurity. This will be exacerbated by the pandemic, climate shock and the locust attacks as the yield and supply chain is disrupted [17].

Globally, in 2019, 47 million children were suffering from stunting and wasting due to acute malnourishment. This is projected to increase by 6.5 million more children due to constraints on nutrition services and limited accessibility. The food prices were adversely impacted throughout the world as COVID-19 disrupted the already fragile supply chains, which resulted in high price volatility for farmers and expensive essential commodities for consumers.

\subsubsection{SDG-3}

SDG-3 is focusing on good health and well-being. It ensures healthy lives and promotes well-being for all at all ages.

For India, there are a total of eight national-level indicators that capture five SDG targets for 2030 outlined under this goal.

We determined that the hospitals are overwhelmed with COVID-19 patients, and it is hampering the standard care required for other patients with acute or chronic ailments. The number of children affected by the COVID-19 pandemic is very less as compared to adults and the elderly, but the pandemic has severely impacted their growth and protection against infectious diseases, indirectly. As the household income will go down, the children, women and the elderly will become more vulnerable, and an increase in infant mortality rate (IMR) is imminent.

Besides, according to a UNICEF report, India is projected to give birth to 20 million babies, i.e. the highest number of births this year during the pandemic. With the majority of healthcare services redirected for pandemic control, neonatal mortality is set to rise [17].

Considering the global impact, with the overwhelming pressure on health systems, disrupted routine health services and constrained access to nutrition services, there will be an estimated 9.8 - $44.8 \%$ increase in under-5 deaths per month and an 8.3-38.6\% increase in maternal deaths per month, over a period of six months in the 118 low- and middle-income countries.

However, there can be a $13 \%$ increase in TB related deaths worldwide, a $23 \%$ increase in malaria cases in Africa and a $100 \%$ increase in malaria-related deaths if the prevention and detection campaigns do not get back on track in the next six months $[18,19]$.

\subsubsection{SDG-4}

SDG-4 is delivering quality education, and it ensures inclusive and equitable quality education and promote lifelong learning opportunities for all.

For India, there are a total of nine national-level indicators that capture four SDG targets for 2030 outlined under this goal. The followings deliver the local and global impacts on SDG-4.

In India, there are more than 15 lakh schools and 50,000 higher education institutions which were closed due to the pandemic. It impacted millions of students as, along with education schools, also took care of the nutritional needs of the children. The inequality of access to the internet across India increased the digital divide, and even though classes were resumed through online mode, many children were left out of the fold. In addition to the above, access to technology in rural India and urban slums is highly gendered. According to a survey by Young Lives, $80 \%$ of the girls in rural areas have never accessed the internet, and $62 \%$ have never used a computer [18].

In the global context, according to a UNESCO report, the COVID-19 pandemic will negatively impact more than 290 million students from 22 countries due to the closure of schools. We predict that extended school closures will weaken the fundamentals of students, and it leads to loss of human capital as well as economic opportunities in the long run. Also, according to the World Bank, COVID-19 will deeply impact countries in where education may be grappling with high 
dropout or low learning outcomes rate. We found that several educational institutions had no choice but to embrace e-learning to sustain the momentum.

We have seen that in the last decade to now, encouraging to use e-learning has become more popular, and it witnessed an uptick due to ubiquitous internet connectivity, the proliferation of smartphones and significant advances in technology. Therefore, there will be a major shift in the curriculum and pedagogy in the post-COVID-19 era. For example, Climate Change Induced Disaster Management in Africa (CIDMA) has developed up-to-date courses in disaster management online courses. Many courses deliver by various institutions such as Coursera made it for free and learned online. For example, one of the courses is Do-It-Yourself Geo Apps, and it delivers how to use Web Application and to create Geo Application. Also, Southwest Jiaotong University (SWJTU) has planned to run MOOC courses, synchronous and asynchronous courses for students.

However, at least 500 million students globally are left out from the digital access to education. Such prolonged absence from school is associated with lower retention and graduation rates and worse learning outcomes, especially students from the disadvantaged section of society $[9,10]$.

\subsubsection{SDG-5}

SDG-5 is gender equality, and it stresses on achieving gender equality and empowering all women and girls.

The followings deliver the local and global impacts on SDG-5.

The local impact of COVID-19 under the lockdown, violence against women, has increased drastically. The domestic violence complaints in the period between March-May were at a 10-year high [19].

Perhaps post COVID-19 situations bring more and more behavioural and mental changes among women, particularly with huge post-traumatic stress. According to the Population Foundation of India, the disruption of routine health services, including pre- and post-natal health care, family planning and contraceptive supply, has put the health of women and girls at increased risk due to decreased access and taken away their control. The female labour force participation rate in India is 25 percent. $90 \%$ of working women are engaged in the informal sector or irregular formal sector, the majority of which is constituted by the hospitality and service sectors. The pandemic would force these women into more vulnerable jobs or result in their permanent exit from the market.

Finally, the pandemic has also disrupted the work of Self-Help Groups (SHGs), which had an important role in women empowerment. With only $46 \%$ of women having access to the mobile phone, digitized credit facilities will be out of reach for them [20].

Globally, we predict that $70 \%$ of the frontline healthcare workers are women putting them at greater risk from the pandemic [9-11]. The campaigns against female genital mutilation and child marriage have come to a halt due to the pandemic, which could severely affect the progress achieved till now. Therefore, due to the lockdown, the burden of unpaid household work and childcare is more than the pre-COVID-19 era, and it would have a long-term effect on women's health.

Besides, there are increased incidences of domestic violence against women during the pandemic lockdown. An estimated increase in 25-30\% of reported cases has been seen in France, Argentina, Cyprus, and Singapore. And in many countries like Germany, Canada, Spain, the UK, the US and other countries, the demand for shelter homes by women has gone up [21].

\subsubsection{SDG-6}

SDG-6 is about clean water and sanitation, and it ensures the availability and sustainable management of water and sanitation for all.

For India, there are a total of seven national-level indicators that capture four SDG targets for 2030 outlined under this goal [5-10]. According to the above, we may provide the following local and global impacts on SDG-5.

Millions of Indians were already at risk due to the infectious diseases from unhygienic water and sanitation conditions. Therefore, we expect that water-borne diseases are more prevalent in rural Indian populations and urban slum dwellers because of inadequate hand washing and unclean 
water. Like these water-borne diseases, the coronavirus can also spread easily when clean water is not available.

As we can see in the world, the pandemic outbreak is projected to slow down investments in the water sector globally [22]. We estimated that the high-risk areas during the pandemic with the most chance of spread are the areas with low access, reliability, and the quality of water, sanitation, and hygiene (WASH). Moreover, industrial water demand will decrease by $27 \%$ due to the pandemic. This would result in reduced revenues to water utilities. There is a partial suspension of water billing and moratoriums on water service cut-offs in low-income countries globally.

\subsubsection{SDG-7}

The goal-7 serves for affordable and clean energy. It ensures access to affordable, reliable, sustainable, and modern energy for all.

For India, there are a total of two national-level indicators that capture one SDG target for 2030 outlined under this goal.

The impact of COVID-19 on SDG-7 estimates as (a) people without access to electricity declined from 1.2 billion to 789 million in 2018, but the world was lagging behind in achieving the targets by 2030 even before the pandemic, this is not expected to improve now with a constraint on funds. (b) There are millions of deaths due to a lack of clean cooking fuel. The progress in this sector is also stagnant since 2010 and is not expected to change. (c) The share of renewable energy is growing at a pace of 1.7 percent only. It is difficult to meet the target at this pace. (d) There is an urgent requirement to provide electricity for 1 billion people who are relying on health facilities without electricity. (e) Global energy investment is predicted to reduce by $20 \%$, or $\$ 400$ billion. (f) Global energy demand could fall by $6 \%$ in 2020 , which would also cause a decrease in Global energy-related CO2 emissions by almost $8 \%$ in 2020, with coal demand also projected to fall by $8 \%$ $[23]$.

\subsubsection{SDG-8}

The goal-8 is decent work and economic growth. It promotes sustained, inclusive and sustainable economic growth, full and productive employment and decent work for all.

For India, there are a total of seven national-level indicators that capture four SDG targets for 2030 outlined under this goal. We can determine the impacts of COVID-19 on SDG-8 as follows.

Locally, the economic impact of the pandemic has been disruptive, with the fourth-quarter growth of FY2020 has slipped to $3.1 \%$ according to the ministry of statistics. Research by State Bank of India estimates the contraction of gross domestic product (GDP) by $40 \%$ in the first quarter of FY21. Unemployment in India rose to $26 \%$ from $6.7 \%$ as a consequence of lockdown, i.e. at least 14 crore people lost employment.

The global impact of COVID-19 could increase the incidences of child labour and pose a serious threat to decent work for especially vulnerable women and men from the informal sector. With the reduction in working hours and economic decline due to the pandemic, labour productivity is expected to go down in 2020. It is estimated that the informal economy constitutes more than half of the workforce, amounting to approximately 1.6 billion workers who are vulnerable and severely affected.

\subsubsection{SDG-9}

The goal-9 is for industry, innovation, and infrastructure. We work together to build resilient infrastructure, promote inclusive and sustainable industrialization and foster innovation.

For India, there are a total of four national-level indicators that capture three SDG targets for 2030 outlined under this goal.

We can describe the local impacts of COVID-19 on SDG-9 as (a) standard \& poor's (S\&P) Bombay Stock Exchange (BSE) India Infrastructure Index lost $35 \%$ of its value during the initial months of the pandemic. That is to say, there is a demand cut in the transportation sector, power 
and industry, which would limit the growth with no clear recovery period insight [24]. Therefore, according to the government data, India's eight key industries in the infrastructure sector shrank $6.5 \%$ in March after the pandemic lockdown. The crude oil sector contracted $5.5 \%$, natural gas $15.2 \%$, refinery products $0.5 \%$, fertilisers $11.9 \%$, steel $13 \%$, cement $24.7 \%$ and electricity $7.2 \%$ in the period of one month [25].

We estimate that the capital expenditure in the infrastructure segment would go down with limitations created due to pandemic for both private and government investments. India's monthly internet user base is estimated to reach 639 million, as reported by the ICUBETM report by Kantar. Currently is rural India, there being 264 million internet users, which is projected to reach 304 million in 2020 with students and housewives to adopting internet services. Some key elements that will drive the impact are Over The Top (OTT), hyperlocal services, social media, communication and online payments [26].

We have also seen that many industries and companies have focused on the development of new technologies and innovative devices and platforms. For example, GeoIME explored the innovative approaches toward reducing the number of inspections of vulnerability and risk estimation of buildings.

Globally $97 \%$ of people live within reach of a mobile signal, and $93 \%$ within reach of a mobile broadband signal. With the pandemic, there is an increased dependence on digital payments, e-learnings and many more, so the internet usage is bound to increase $[9,10]$.

\subsubsection{SDG-10}

The goal-10 focuses on the reduced inequalities. Everyone works on reducing inequality within and among countries.

For India, there are a total of nine national-level indicators that capture three SDG targets for 2030 outlined under this goal. We express the local and global impact as follows.

In India, the social distancing and lockdowns have led to the increase in income inequalities as the poorer segments of society who are engaged in informal sectors and other physical work for their livelihood are severely impacted as their work cannot be done remotely.

We observed that the educated white-collar employees working in Information Technology (IT) sector, finance and similar sectors had not faced many severe consequences as their work can be done remotely. Besides, the poorer segments have very few savings, which will be depleted by the end of this pandemic, and there is a lack of access to credit for them, which has put them in dire straits. Therefore, economists believe that due to the lockdown, there will be a widening in the gaps in access to quality education between high and low-income households. This will have far-reaching consequences in the future as the employment opportunities for low-income people reduce. Finally, the migrant labour community has suffered the brunt of the COVID-19 pandemic both economically and socially as they lost their livelihoods and forced to abandon the cities.

We also observed that globally the workers are receiving less share of what they help produce; with the pandemic, these workers have altogether lost employment, and with decreased production, their incomes have also contracted. Disabled people will be facing more challenges, be it the term of access to education, health care or the stigma attached. Finally, with the pandemic, there would be a reduction in the influx of money into developing and least developed countries from the developed nations of the world. This would turn back the progress achieved till now and widen the gap between the countries $[9,10]$.

\subsubsection{SDG-11}

The goal-11 provides sustainable cities and communities, and it makes cities and human settlements inclusive, safe, resilient, and sustainable.

For India, there are a total of five national-level indicators that capture two SDG targets for 2030 outlined under this goal. The impacts of the COVID-19 on SDG-11 can be considered for both local and global scales.

The air quality improved exponentially in Delhi, one of the most polluted cities in India. PM10 and PM2.5 concentrations in the air were reduced by half, $\mathrm{NO} 2$ and $\mathrm{CO}$ concentration also went 
down. In the transportation and industrial locations, the air quality improved as much as by $60 \%$ [27].

India has made special guidelines for dealing with the biomedical waste generated from dealing with the pandemic. App-based technologies are being used to monitor and streamline the disposal of waste [28]. In addition to the above, the population living in slums has decreased exponentially due to the large-scale migration back to rural areas after the pandemic shock. But this is a temporary change which is expected to change. However, the pandemic has pushed to rethink the current model of high-density habitation in cities. The high-density populations in metros like Mumbai and Delhi have created diseconomies and hampered the efficient dealing with the pandemic.

We predict that on a global scale, the people living in slums and informal settlements have suffered because of a lack of access to basic amenities like water, sanitation, waste management and similar challenges and issues. They are overcrowded and social distancing in such places is next to impossible in such a scenario; these places became hotspots of the pandemic. We have seen that the need for more public transport has arisen throughout the world to tackle the problem of overcrowding and address the need for social distancing. Therefore, the pandemic has pushed to rethink the urban cities. It has made clear that for better public health and mitigation of people's vulnerabilities, urban planning is crucial. Of the 150 countries having some kinds of urban plans, many are revisiting the plans to make them more sustainable.

Finally, we can say that air pollution is estimated to have caused 4.2 million premature deaths globally in 2016. With COVID-19 induced lockdowns, many of the cities saw a major drop in air and water pollutants as the factories were closed, and the automobiles decreased $[9,10]$.

\subsubsection{SDG-12}

Responsible consumption and production are goal-12. It ensures sustainable consumption and production patterns.

For India, there are seven national-level indicators that capture three SDG targets for 2030 outlined under this goal.

The domestic demand for steel has reduced in the range of $12 \%$ to $20 \%$ in FY 2020-21, showing a slowdown in the consumption of end products using steel. Fertilizer sales increased by $45 \%$ even amid the pandemic as there was no restriction on the fertilizer industry. Besides, with the experts suggesting hand wash as the most effective precaution against the pandemic, the water demand is predicted to go up by $20-25 \%$ as per household would need 100-200 liters more water [29].

A study by Jal Jan Jodo Abhiyan has found out that in the water scarce Bundelkhand region, per capita water usage has gone up by $60 \%$ after the pandemic as people are washing hands at least five times a day [30]. If this continues, it will prove difficult in the long run for the state to manage water supply for every household in the region.

Globally $13.8 \%$ of the food produced is lost during transport, storage, and processing, which amounts to $\$ 400$ billion annually. It is highest in South Asia and Africa. With the pandemic disrupting already fragile supply chains this year, the losses of perishables are bound to be higher than in previous years.

\subsubsection{SDG-13}

The goal-13 is climate action, and it takes urgent action to combat climate change and its impacts.

For India, there are a total of four national-level indicators that capture two SDG targets for 2030 outlined under this goal.

The impacts of COVID-19 on climate action are determined. According to experts and newspaper reports, the lockdowns established as a precautionary measure against the pandemic has resulted in improvement of air and water quality across the globe. Also, the pandemic has exposed the vulnerabilities within our emergency response, governance, and early warning systems, which are important from the viewpoint of managing the disasters occurring due to climate change.

We observed that climate action had taken a backseat, and it is predicted to be slower than before as the focus and resources at state and national level have been redirected towards dealing with COVID-19 in India. We predicted that with the visible positive effects of lockdown on the 
environment, a stronger case for sustainability might be built with a greater push for alternative solutions like electric vehicles and rooftop solar power.

\subsubsection{SDG-14}

Goal-14 is for life below water, and it describes the conserve and sustainably use the oceans, seas, and marine resources for sustainable development.

For India, there are a total of five national-level indicators that capture four SDG targets for 2030 outlined under this goal.

We determined the impacts of COVID-19 to SDG-14 are not only reducing the economic activities but also much needed time for the water bodies to recuperate. However, the impacts are (a) the reduced human and economic activities have given much needed time for the water bodies to recuperate, the ponds, irrigation canals and lakes are many cleaners [31, 32].

In addition to the above, the pandemic crisis has adversely affected the livelihoods of small-scale fishermen as the global demand for seafood reduced, and the supply chain disruptions happened due to transport restrictions and limited market access. Therefore, a pandemic can increase the incidences of piracy, poaching and smuggling in the coastal regions, and illicit fishing might also increase with fewer resources to monitor the coastal areas. Also, industrial fishing will come down due to the fear induced by the pandemic, and it would prove beneficial to the artisanal fishers who have now reduced competition from the industrial fisheries [33].

Finally, there is a reduced use of chemical fertilizers and other human activities near the water bodies and in coastal regions, which has helped improve the quality of water by reducing the biochemical oxygen demand.

\subsubsection{SDG-15}

It is for life on land and describes how to protect, restore and promote sustainable use of terrestrial ecosystems, sustainably manage forests, combat desertification, and halt and reverse land degradation and halt biodiversity loss.

We have found that the impact of COVID-19 on many infectious diseases. These infectious diseases have been found to be of zoonotic origin, specifically transmitted from wildlife to human beings. The threat of such pandemic breaks increases with an increase in deforestation, habitat loss and illegal poaching.

For India, there are a total of five national-level indicators that capture five SDG targets for 2030 outlined under this goal.

\subsubsection{SDG-16}

Peace, justice, and strong institutions deliver in goal-16. It promotes peaceful and inclusive societies for sustainable development, provides access to justice for all and build effective, accountable, and inclusive institutions at all levels.

For India, there are a total of five national-level indicators that capture five SDG targets for 2030 outlined under this goal.

As we discussed in the previous sections, similar impacts almost have been seen in goal-16 as well. We describe the impacts as follows:

The pandemic has disrupted humanitarian aid flows, has limited the peace operations, and postponed or diverted the parties involved in the conflict from diplomacy. This might increase the unrest as conflicts arise within and among the countries.

We have also seen that there is already geopolitical friction created due to COVID-19 as the US has been blaming China for the novel coronavirus breakout, and China has been trying to gain favour by offering international aid to many countries. However, the authors do not believe this blame as it makes the current situation more complex to achieve the SDGs 2030, and these political frictions may create serious challenges and impacts on various collaborations, communications, and engagements. 
Also, in some areas, there is also a chance of increased cooperation, as in the case of the UAE and Kuwait, who offered humanitarian aid to Iran. Moreover, China cooperated in providing humanitarian aids to several countries such as Iran, Italy, Argentina, Germany, and some African countries. The countries directly affected due to conflict have become vulnerable to the pandemic outbreak. Because their health systems are already broken, and the additional pressure of a global health crisis of this scale would put unprecedented demands on the system, which it is not capable of handling. For example, in Libya, during the war, most of the foreign medics had left the country, and in Venezuela, the political standoff had impacted the health system adversely.

\subsubsection{SDG-17}

Goal-17 encourages everyone to have a partnership for the above goals. It strengthens the means of implementation and revitalizes the global partnership for sustainable development.

Like the other SDGs, the impacts of COVID-19 have changed the nature of the collaborations. These impacts can be described as (a) remittances to low- and middle-income countries from international sources, which gave an economic lifeline for many poor households in these countries is projected to fall from $\$ 554$ Billion in 2019 to $\$ 445$ Billion in 2020. (b) Global foreign direct investments are expected to fall by $40 \%$ in 2020. (c) Net official development assistance from the member countries of the Development Assistance Committee (DAC) is expected to fall as the pandemic puts more pressure on the donor's aid budget. (d) There are instances where new partnerships have been forged. To develop a unified continent-wide strategy to deal with the pandemic and its impact, the African Union has established an Africa Taskforce for Coronavirus (AFTCOR). (e) The partnership between the African Union and the UN and has also been strengthened to deal with the pandemic outbreak [34]. (f) The European Union and the Member States have created 'Team Europe', which is helping the partner countries in dealing with COVID-19 through a comprehensive and decisive action to strengthen the healthcare, water and sanitation systems. Also, they collaborated to ensure fast and equitable access to safe, quality, effective and affordable tests, treatments and vaccines against coronavirus for the partner countries [35]. (g) WHO has initiated a Research and Development (R\&D) Blueprint to accelerate the development of diagnostics, vaccines, and therapeutics for the fight against COVID-19. It has made a multinational coordinated research group for the purpose [36]. (h) In India, NITI Aayog CEO Amitabh Kant has reported the creation of empowered groups by the government, which constitute the NGOs, private sector and international aid agencies for tackling the COVID-19 crisis. The partnerships between these stakeholders are encouraged to lead an efficient fight against the pandemic [37].

\subsection{Analysis and Interpretation}

In the following diagram (Figure 40.1), the impact of the COVID-19 pandemic on sustainable goals has been mapped along with the interaction between different sustainable goals since each goal is affected by the progress of other goals (Table 40.1). The 17 sustainable development goals do not exist in isolation; there is a synergy among all goals. This synergy has been depicted through various linkages on the map. The analytical brainstorming and interpretational approach associated with some surveys attempted to define logical relationships among SDGs. We collected data and reports from various resources. We considered national and global level targets and indicators for SDGs. The SDGs targets and indicators are used as elements to interpret the relationships of 17 SDGs. 


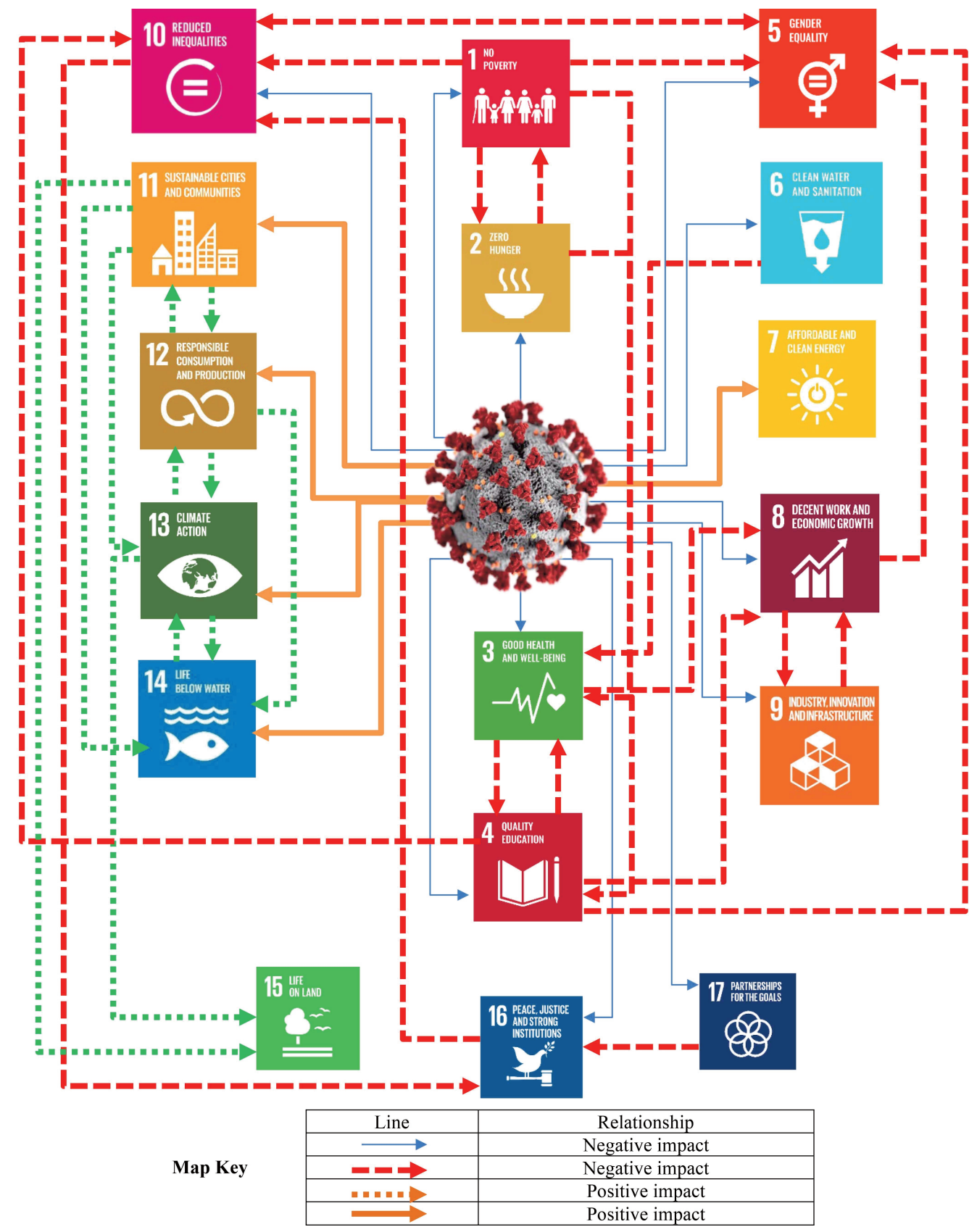

FIGURE 40.1

Impact of COVID-19 pandemic on SDGs 2030

(Source: Created by qualitative analysis of collated information of the impact of COVID-19) 
TABLE 40.1

Summary of COVID-19 impacts on SDGs for local and global scales

\begin{tabular}{ll} 
Goals & \multicolumn{1}{c}{ Local Impact } \\
\hline 1 - No Poverty & $\begin{array}{l}\text { India is estimated to have } 68 \% \text { population } \\
\text { below } \$ 3.2 / \text { day because of lack of livelihoods } \\
\text { and disruption of the informal sector which } \\
\text { involves } 90 \% \text { of the workforce }\end{array}$ \\
\hline 2 - Zero Hunger & $\begin{array}{l}\text { ICDS Scheme, Mid-Day Meal Scheme have } \\
\text { been compromised. Food supply chains have } \\
\text { been disrupted - heavy post-harvest losses } \\
\text { even with bumper production. }\end{array}$ \\
\hline 3 - Good Health & $\begin{array}{l}\text { Most adversely affected. Lack of sufficient } \\
\text { healthcare workers and facilities. TB and } \\
\text { and Well-Being care would be drastically affected. }\end{array}$
\end{tabular}

4 - Quality

Education

Unequal access to technology is predicted to cause a $20 \%$ drop out of girl students, disrupt the foundations of all students, and hurt their opportunities of better jobs.

\section{5 - Gender \\ Equality}

Increased domestic violence against women. Loss of livelihoods which could result in a permanent exit from the market. Healthcare and nutrition for women are also severely impacted.

6 - Clean Water The burden on the sanitation system and and Sanitation clean water availability is stretched in the cities. More than a crore people have migrated back to rural areas putting stress on sanitation in rural areas where although the toilets are built, they still need to be cleaned manually.

\begin{tabular}{ll}
$\begin{array}{l}\text { 7 - Affordable } \\
\text { and Clean } \\
\text { energy }\end{array}$ & $\begin{array}{l}\text { There is an urgency to provide electricity to } 1 \\
\text { facilities without electricity. There is an estin } \\
\text { and } 6 \% \text { reduction in global demand. }\end{array}$ \\
\hline $\begin{array}{l}\text { 8- Decent } \\
\text { Work and }\end{array}$ & $\begin{array}{l}\text { Economic growth has slipped to } 3.2 \% \text {, and } \\
\text { Economic }\end{array}$ \\
\hline
\end{tabular}

Economic

Growth

9 - Industry,

Innovation, and

Infrastructure

Investments in infrastructure have gone

down. The sector has shrunk by $6.5 \%$. Eight key industries, i.e. crude oil, refinery, fertilizers, steel, cement electricity and natural gas, all have shrunk. Internet and mobile users are estimated to go up.

10 - Reduced

Inequalities are bound to increase with many Inequalities blue-collar workers out of jobs while the white-collar workers work online to earn their livelihoods. With education also impacted the inequalities will further increase in the long run.

11 - Sustainable Air quality has exponentially improved. New

Cities and

Communities

processes for BMW management have been streamlined. Rethinking of high-density city planning is triggered.

12 - Responsible Consumption and Production

Water demand is estimated to increase by $20-$ $25 \%$. Fertilizer demand has also spiked. Steel demand has gone down and estimated to further reduce by $20 \%$. Consumption is majorly focused on essential commodities

Impact on Other

SDGs

Global poverty is estimated to go up by $8.8 \%$. Decreased labour income and poor job quality will push people into extreme poverty.

10,000 child deaths every month are recorded. Nutrition services have taken a hit. More than 2 billion are facing food insecurity. Estimated double-digit increase in child and maternal mortality, TB and HIV related deaths due to disruption of routine healthcare services.

Globally 290 million students will be impacted across 22 countries, and 397 million have lost out on food due to school closure. 500 million children and youth are not able to take the benefit of digital learning.

$25-30 \%$ increase in domestic abuse cases. The shutdown of prowoman campaigns. Increased stress and burden due to lockdowns

$2,3,4,5,10$

$1,3,4,5,8,10$

$1,2,4,5,8,10$

Capital expenditure on water and sanitation is expected to go down by $7 \%$ as the industrial demand has gone down, and the funds are directed for COVID-19 relief.

billion people who are dependent on healthcare mated reduction of $20 \%$ in energy investments Child labour is predicted to increase. Women might be pushed into dangerous jobs. The informal sector is adversely affected. Tourism and hospitality industry too.

Globally there is a $6 \%$ decline in the manufacturing sector. Internet users are projected to go up. SMEs are projected to decline due to a lack of credit facilities.

According to studies on previous pandemics, it has been observed that inequalities undoubtedly increase after such shock. The gap will widen between developed and developing and LDCs as funding are diverted or stopped in the wake of the pandemic.

Air and water quality in the cities have improved. Many of the 150 countries are rethinking the city plans to make them more sustainable.

Local sourcing and online working promoted due to the pandemic has reduced the demand for unsustainable fossil fuels and made a start towards responsible consumption now.

\begin{tabular}{l}
\hline 13 - Climate \\
Action \\
\hline 14 - Life Below \\
Water \\
\hline 15 - Life on \\
Land \\
\hline 16 - Peace, \\
Justice, And \\
Strong \\
Institutions \\
\hline $17-$ \\
Partnerships for \\
the Goals
\end{tabular}
$6 \%$ reduction in global emissions. Vulnerabilities exposed; space has been created for designing of policies. For now, funds have been diverted to COVID-19 relief so climate action might be limited.

Water bodies are cleaner due to reduced human and industrial activity. Local fishermen are benefitting due to reduced industrial fishing. Water bodies and the fish stock got the recuperation time during the pandemic season No direct impact of Covid-19 but as a result of increased awareness about zoonotic diseases the laws against smuggling, protecting wildlife etc. might become stricter. Internal conflicts have been put to rest for the time being as countries grapple with the pandemic. But International conflicts might increase due to increasing friction between US and China and unscrupulous politicians as the diplomacy efforts are restricted during these times.

All new partnerships are being forged for dealing with novel corona virus. In the process

the Goals other goals are getting side-lined. But all the stakeholders the government, NGOs, private businesses, and international organizations are learning to work together. 


\subsection{Summary and Conclusion}

We concluded that the pandemic had had severe impacts on the whole world, including India and the world. This is a public health crisis of unprecedented proportions that came as a shock and caught the world unprepared. By the end of 2020, 21 of the 169 SDGs targets would have matured, but the progress was already slow as the world was lagging behind in achieving the mentioned targets. This lethargic progress is further impacted by the sudden shock of the pandemic. It is expected that decades of progress in achieving the goals might be reversed because of this shock. The degree of impact might vary, but each and every single goal from the 17 SDGs has been affected either positively or negatively. All the goals are interconnected with the impact on one goal will have an impact on the other. Some goals like SDG 1, SDG 2, SDG 3, have seen a serious rollback in progress with more and more people losing livelihoods and slipping back into poverty, increased hunger crisis and insufficient healthcare system capacities. This has negatively impacted SDG 4, and in the long run, it will affect SDG 8 as the opportunities for decent work go down with a reduction in quality education opportunities. With the limited resources, capacities, and burgeoning crisis, the inequalities will increase for women and the poor, thus reversing the progress in SDG 5 and SDG 10. Some positive strides have been observed for SDG 7, SDG 11, SDG 12, SDG 13 and SDG 14 as the pandemic forced people to rethink the way cities were being developed and the lockdowns gave space for the environment to recuperate, the pressure on water life decreased as people become more conscious and responsible about their consumption and production. The pandemic also gave time to think and plan about the seriousness of the impending climate crisis. It brought to the forefront the weaknesses in current social, economic and governance systems of the world.

The COVID-19 experiences from various countries indicated that the more information we can access and analyze, the more effective nations we have. Therefore, it leads partners, including multilateral organizations and citizens, to explore and determine solutions for a disaster such as COVID-19 pandemic. This collaboration of partners requires several key components, such as existing and accessible geospatial information and the spatial data infrastructure (SDI) built. The geospatial information requires the integration of statistics and use it in various geography in a local, national, and global scale. We need technologies to demonstrate our geographic dimension on a global scale. It considers information that can be conveyed in a clearer and more useful manner than statistical data $[38,39]$. In other words, we are fundamentally beyond the technologies and track platforms to enable visualization. This process relies on the people partnerships and the method of collaborations on how to build the ability to come together towards a shared purpose to remove barriers. However, the experiences of partnerships to data sharing of spatial information can also be considered to support COVID-19 response and recovery at this hard-pandemic situation and SDG2 2030.

We suggest empowering the implementation of geospatial technologies and methods such as Web App and Geo App. However, perhaps India requires speeding up to adopt these approaches. The adoption of spatial approaches such as Web App, Geo App, and smart mapping to spatial epidemiology, disease surveillance, and implementation of health policies in India has great potential for both success and efficacy. It is because India has a large population, ongoing public health challenges, and a growing economy with an emphasis on innovative technologies.

\section{Acknowledgement}

The authors thank the United Nations for providing information on the COVID-19 pandemic. We dedicate the chapter to people and families in the world who lost their beloved due to the COVID-19 pandemic disaster. 


\section{References}

[1] SDG Indicators. Global indicator framework for the Sustainable Development Goals and targets of the 2030 Agenda for Sustainable Development. 2020. Retrieved on 27 July 2020.

[2] United Nations Sustainable Development Group. Finding transformative pathways in turbulent times. The sustainable development goals report, 2020. Retrieved on 27 July 2020.

[3] United Nations Sustainable Development Group. Shared Responsibility, Global Solidarity: Responding to the socio-economic impacts of COVID-19. 2020. Retrieved on 27 July 2020.

[4] United Nations High-Level Political Forum for Sustainable Development. The decade of action taking SDGs from Global to Local, India Voluntary National Review 2020. 2020. Retrieved on 27 July 2020.

[5] United Nations. SDG India: Index and Dashboard 2019-2020 Report1. 2020.

[6] Homi Kharas and Kristofer Hamel. The COVID-19 effect: Poverty headcount to rise the most in India. 10 million to be affected. 2020. 8 May 2020.

[7] Pallavi Nahata. Work Under MGNREGA Falls to Lowest in Five Years. 2020. URL https://www. bloombergquint.com/economy-finance/work-under-mgnrega-falls-to-lowest-in-five-years. 30 April, 2020.

[8] Shivani Chaudhry, Anagha Jaipal, and Aishwarya Ayushmaan. Housing and Land Rights Network. Human Rights Assessment and Compilation of State Relief Measures. 2020.

[9] United Nations. Sustainable development goals report 2020. 2020.

[10] United Nations. SDG India: Index and Dashboard 2019-2020 Report 2. 2020.

[11] Pramitha Elizabeth Pothan, Makiko Taguchi, and Guido Santini. Local food systems and COVID-19: A glimpse on India's responses. FAO, 2020. 22 April, 2020.

[12] URL https://www.news18.com/news/india/shortage-of-labour-and-machinery-during-covid-19-lockdownworsens-indias-agrarian-crisis-2580143.html.

[13] URL https://smefutures.com/covid-19-rumours-fake-news-slaughter-poultry-industry-rs-22500-crorelost-5-crore-jobs-at-stake/.

[14] URL https://www.newindianexpress.com/cities/delhi/2020/jun/29/malnutrition-among-children-theunspoken-side-of-covid-19-pandemic-2162806.html.

[15] URL https://www.financialexpress.com/industry/agriculture-gva-growth-in-fy21-seen-at-2-5/1981655/.

[16] URL https://economictimes.indiatimes.com/news/economy/agriculture/record-grain-output-in-2020horticulture-to-grow-too/articleshow/73684423.cms.

[17] UNICEF. Millions of pregnant mothers and babies born during COVID-19 pandemic threatened by strained health systems and disruptions in services. UNICEF. Press Release, 2020. URL https://www.unicef.org/ rosa/press-releases/millions-pregnant-mothers-and-babies-born-during-covid-19-pandemic-threatened. 6 May, 2020.

[18] Rhiannon Moore and Lydia Marshall. Access to digital learning during COVID-19 closures: compounding educational inequality? 2020. Retrieved on 27 July 2020.

[19] URL https://www.thehindu.com/data/data-domestic-violence-complaints-at-a-10-year-high-during-covid19-lockdown/article31885001.ece.

[20] Niaz M Asadullah and Kalyani Raghunathan. Tackling India's deepening gender inequality during COVID-19. 2020. URL https://blogs.lse.ac.uk/southasia/2020/07/08/tackling-indias-deepening-gender-inequalityduring-covid-19\%.

[21] United Nations Women. Policy Brief: The Impact of COVID-19 on Women. 2020.

[22] George Butler, Rogerio G. Pilotto, Youngki Hong, and Emelly Mutambatsere. The Impact of COVID-19 on the Water and Sanitation Sector. International Finance Corporation (IFC), 2020.

[23] United Nations. Policy briefs in support of the high-level political forum 2020. Accelerating SDG7 achievement in the time of COVID-19. 2020.

[24] Pratik Sengupta. Infrastructure Sector and Investor Valuations Impact Amidst COVID-19. International Finance Corporation (IFC), 2020. URL https://www.duffandphelps.com/about-us/news/infrastructuresector-investor-valuations-impact-covid-19. 23 April 2020. 
[25] URL https://www.deccanherald.com/business/business-news/coronavirus-impact-india-s-keyinfrastructure-sector-output-contracts-in-march-831876.html.

[26] URL https://www.livemint.com/news/india/covid-19-to-push-india-s-monthly-active-internet-user-baseto-639-mln-kantar-11588758259831.html.

[27] Susanta Mahato, Swades Pal, and Krishna Gopal Ghosh. Effect of lockdown amid covid-19 pandemic on air quality of the megacity delhi, india. Science of The Total Environment, 730:139086, 2020.

[28] URL https://timesofindia.indiatimes.com/india/dealing-with-biomedical-waste-in-the-time-of-covid19-presents-huge-challenge/articleshow/75905790.cms.

[29] URL https://www.downtoearth.org.in/blog/water/covid-19-outbreak-more-hand-washing-can-increaseindia-s-water-woes-69900.

[30] URL https://economictimes.indiatimes.com/news/politics-and-nation/water-consumption-in-parchedbundelkhand-up-60-percent-due-to-covid-19-study/articleshow/75107081.cms?from=mdr.

[31] URL https://www.thehindu.com/sci-tech/energy-and-environment/lockdown-due-to-covid-19-how-ourwaterbodies-are-cleaner/article31518267.ece.

[32] Ali P. Yunus, Yoshifumi Masago, and Yasuaki Hijioka. Covid-19 and surface water quality: Improved lake water quality during the lockdown. Science of The Total Environment, 731:139012, 2020.

[33] W. Saumweber, K. Luhr Amy, and Ty Lo.

[34] URL https://www.un.org/africarenewal/web-features/coronavirus/osaa/covid-19-strong-internationalpartnerships-key-bolstering-africa's-response.

[35] URL https://ec.europa.eu/international-partnerships/topics/eu-global-response-covid-19_en.

[36] WHO. Public statement for collaboration on COVID-19 vaccine development. 2020. URL https://www. who. int/news-room/detail/13-04-2020-public-statement-for-collaboration-on-covid-19-vaccine-development.

[37] URL https://indianexpress.com/article/opinion/columns/ngos-private-sector-internationalorganisations-fight-against-covid-amitabh-kant-6425547/.

[38] A. Laaribi and L. Peters. GIS and the 2020 Census: Modernizing Official Statistics. Esri Press, 2019.

[39] Saied Pirasteh and Masood Varshosaz. Geospatial information technologies in support of disaster risk reduction, mitigation and resilience: Challenges and recommendations. In A. Rajabifard, editor, Sustainable Development Goals Connectivity Dilemma, chapter 6, pages 93-105. CRC Press, 2019. 